\title{
Patients treated in a coronary care unit without acute myocardial infarction Identification of high risk subgroup for subsequent myocardial infarction and/or cardiovascular death
}

\author{
R. NORDLANDER AND O. NYQUIST \\ From the Department of Medicine, Karolinska Institutet at Huddinge Hospital, Stockholm, Sweden
}

SUMMARY Consecutive patients admitted to a coronary care unit (CCU) during one year were studied. The diagnosis of acute myocardial infarction was not substantiated by our criteria in 206 of the patients discharged from the CCU. Of these, 193 were retrospectively followed up during one year. Seventeen of the patients $(9 \%)$ died from cardiovascular causes during the 1-year period. Another 14 patients $(7 \%)$ had a subsequent non-fatal acute myocardial infarction during the same period. The majority of the patients had coronary artery disease. Only $32(17 \%)$ could be classified as non-coronary cases, and these had an excellent prognosis without any subsequent acute myocardial infarctions or deaths.

The occurrence of transient ST-T shifts in serial electrocardiograms obtained during the first 3 days in hospital selected a subgroup of patients who had a high risk for subsequent non-fatal acute myocardial infarction and/or cardiovascular death. This high risk subgroup provides a basis for more aggressive diagnostic and therapeutic intervention.

Increasing effort is made to identify patients at high risk for sudden death or acute myocardial infarction (Solomon et al., 1969; Freeman and Loughhead, 1972; Helmers, 1974; Corday, 1977; Moss et al., 1977; Vedin et al., 1977; Vismara et al., 1977). This is even more challenging since recent reports indicate the possibility of preventive measures (Ahlmark et al., 1974; Wilhelmsson et al., 1974; Multicentre International Study, 1975). Most studies in this field have been performed on patients with acute myocardial infarction (Ahlmark et al., 1974; Helmers, 1974; Wilhelmsson et al., 1974; Multicentre International Study, 1975; Moss et al., 1977; Vedin et al., 1977). However, in a recent study of patients admitted to a coronary care unit (CCU) with suspected acute myocardial infarction the diagnosis was unconfirmed by serial electrocardiograms and estimations of serum enzyme levels in 70 per cent. These patients had the same high risk of cardiovascular death as the patients discharged with a diagnosis of acute myocardial infarction with a 1-year and 2-year mortality of 10 and 20 per cent, respectively (Schroeder et al., 1977). Therefore this study was undertaken with

Received for publication 11 August 1978 the aim of identifying a high risk subgroup for subsequent non-fatal acute myocardial infarction and/or cardiovascular death among the patients discharged from the CCU without a diagnosis of acute myocardial infarction.

\section{Subjects and methods}

A consecutive series of patients admitted to the CCU of Huddinge Hospital from 1 January 1975 to 1 January 1976 was retrospectively studied. The admission criteria were: (1) central chest pain lasting for more than 15 minutes beginning within the previous 48 hours; (2) frank pulmonary oedema without previously known valvular lesion, uraemia, or intoxication; (3) shock without suspicion of acute hypovolaemia or intoxication; (4) syncope with electrocardiographic suspicion of acute myocardial infarction; (5) intractable angina pectoris. The criteria for a diagnosis of acute myocardial infarction was the fulfilment of $a, b$, or $c$ below in addition to one of the admission criteria: (a) appearance of a pathological $Q$ wave and/or appearance or disappearance of a localised pathological ST elevation followed by $T$ inversion in at least 2 electrocardiographic leads in serial electrocardiograms; 
(b) two serum AST (SGOT) values above the upper reference limit with a maximum about 24 hours after onset of symptoms in combination with lower serum ALT (SGPT) values; (c) findings at necropsy of a fresh myocardial necrosis. Patients partly fulfilling the criteria received a diagnosis of suspected acute myocardial infarction. This diagnosis was ruled out in patients not fulfilling any of the criteria a, b, or c. If a patient was admitted several times without a diagnosis of acute myocardial infarction only the first occasion was considered. All patients were clinically examined on admission and twice daily. Heart rate, respiratory rate, blood pressure, and arrhythmias were noted in a data chart.

A standard 12-lead electrocardiogram was obtained on admission and each morning during the following 3 days. Leads I, II, III, aVR, aVL, aVF, $C_{4} R$, $\mathrm{CR}_{1}, \mathrm{CR}_{2}, \mathrm{CR}_{4}, \mathrm{CR}_{5}$, and $\mathrm{CR}_{7}$ were used and the electrode positions were indicated on the chest wall by a marker pen to secure the same electrode positions in succeeding electrocardiograms. The electrocardiograms were recorded with a paper speed of $50 \mathrm{~mm}$ per second and with an amplification of $1 \mathrm{mV}$ per $10 \mathrm{~mm}$. A QRS duration over $0.12 \mathrm{~s}$ was defined as bundle-branch block. A transient ST shift was defined as an elevation or a depression of the ST segment of $1.5 \mathrm{~mm}$ or more compared with the preceding electrocardiogram regardless of the initial ST level. A transient $T$ shift was considered when the $T$ wave changed from a positive to a negative configuration or vice versa, regardless of the amplitude. The $S T$ and/or $T$ shifts should occur in at least 2 of the 12 electrocardiographic leads during the first 3 days. Serum AST (SGOT) and ALT (SGPT) were routinely analysed from samples obtained on admission and every day at 8 am and $8 \mathrm{pm}$ for 3 days.

The patients were followed up after one year. The majority of them were periodically controlled as outpatients. Those not seen by us were traced and interviewed. Information was also obtained from private doctors and from records of other hospitals. Information about deaths was obtained from relatives, private doctors, and from the Government Institute for Forensic Medicine. Sudden death was defined as death occurring within 24 hours from onset of the acute illness. Instantaneous death was referred to as death occurring within minutes.

The significance of differences between mean values was tested by Student's $\mathrm{t}$ test. The $\chi^{2}$ test with Yates' correction was used for testing the significance of differences of relative numbers. Differences with $\mathrm{P}>0.05$ were considered not significant.

\section{Results}

During the 1-year period there were 187 patients with acute myocardial infarction and suspected acute myocardial infarction, but the diagnosis of acute myocardial infarction was not confirmed in 206 of the patients discharged from the CCU. A reliable follow-up could not be obtained in 13 patients $(6 \%)$. Of the remaining 193 patients, 125 were men and 68 were women, with a mean age of 61 years, ranging from 30 to 89 years. Sixty-six patients $(34 \%)$ had a history of previous myocardial infarction (Table 1). Fifty-four patients had a history of hypertension, 18 a history of diabetes mellitus, and 7 patients were treated for hyperlipaemia. One hundred and thirty-four patients $(69 \%)$ had a history of angina pectoris. The duration of angina was 1 month or less in 13 cases and between 1 and 3 months in 4 cases.

During the CCU stay the following complications appeared (Table 2): Nine patients developed left heart failure, 3 patients hypotension and/or shock, 2 patients atrioventricular block I and/or II, 6

Table 1 Previous diseases and mean age

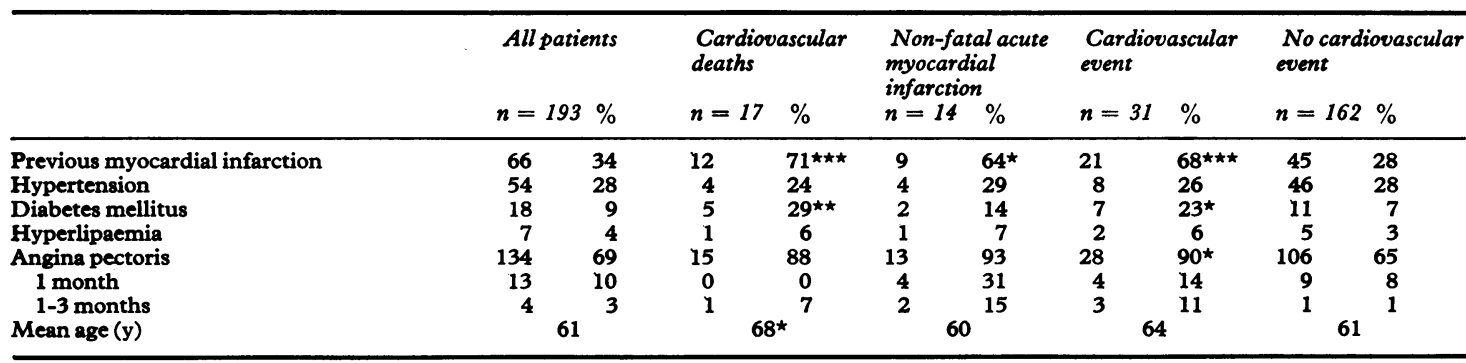

$\star \mathbf{P}<0.05$

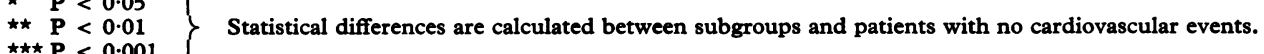


Table 2 Complications appearing in CCU

\begin{tabular}{|c|c|c|c|c|c|c|c|c|c|c|}
\hline & \multicolumn{2}{|c|}{ All patients } & \multicolumn{2}{|c|}{$\begin{array}{l}\text { Cardiovascular } \\
\text { deaths }\end{array}$} & \multicolumn{2}{|c|}{$\begin{array}{l}\text { Non-fatal acute } \\
\text { myocardial } \\
\text { infarction }\end{array}$} & \multicolumn{2}{|c|}{$\begin{array}{l}\text { Cardiovascular } \\
\text { event }\end{array}$} & \multicolumn{2}{|c|}{$\begin{array}{l}\text { No cardiovascular } \\
\text { event }\end{array}$} \\
\hline & $n=193$ & $\%$ & $n=17$ & $\%$ & $n=14$ & $\%$ & $n=31$ & $\%$ & $n=162$ & $\%$ \\
\hline Left heart failure & 9 & 5 & 3 & 18 & 0 & 0 & 3 & 10 & 6 & 4 \\
\hline Hypotension/shock & 3 & 2 & 0 & 0 & 0 & 0 & 0 & 0 & 3 & 2 \\
\hline AV block I/II & 2 & 1 & 0 & 0 & 0 & 0 & 0 & 0 & 2 & 1 \\
\hline Atrial fibrillation/flutter & 2 & 1 & 0 & 0 & 0 & 0 & 0 & 0 & 2 & 1 \\
\hline Ventricular tachycardia & 10 & 5 & 3 & 18 & 1 & 7 & 4 & 13 & 6 & 4 \\
\hline
\end{tabular}

patients sinus bradycardia, 2 patients atrial fibrillation or flutter, and 10 patients ventricular tachycardia. The mean stay in the CCU was 24 hours and in the hospital 6 days.

During the 1-year follow-up 31 patients had at least 1 cardiovascular event. Twenty-three patients had acute myocardial infarction. Four of these died, 2 from sudden death, 1 from cardiogenic shock, and 1 from severe left heart failure. Of the remaining 19 hospital survivors there were 5 subsequent deaths without clinical or necropsy evidence of reinfarction. Three of these deaths occurred suddenly and 2 were the result of severe left heart failure. Eight patients died without evidence of acute myocardial infarction during the follow-up period, 5 from sudden death and 3 from severe left heart failure. Altogether there were 17 cardiovascular deaths and 14 patients with a non-fatal acute myocardial infarction (Fig. 1).

\section{CARDIOVASCULAR DEATHS}

Ages in this group varied between 47 and 85, mean 68 years. Previous diseases, physical findings on admission, and complications appearing in the CCU are shown in Tables 1 and 2 . Seven $(41 \%)$ of the 17 cardiovascular deaths occurred within 3 months and $11(65 \%)$ within 6 months. Ten patients died suddenly, 4 of them instantaneously. Seven patients died from pump failure. Necropsy was performed in 12 cases.

NON-FATAL ACUTE MYOCARDIAL INFARCTION Ages in this group varied between 45 and 75, mean
60 years. Previous diseases, physical findings on admission, and complications appearing in the CCU are shown in Tables 1 and 2. Non-fatal acute myocardial infarctions were more often associated with a history of previous myocardial infarction. Nine $(64 \%)$ occurred within 3 months. The acute myocardial infarctions were diagnosed in hospital by enzymes and/or electrocardiogram in all patients but one. This outpatient's electrocardiogram showed fresh pathological $Q$ waves in several leads of the anterior wall.

There were no significant differences in complications appearing in the CCU, maximal AST (SGOT) values or maximal AST (SGOT) change between patients with cardiovascular deaths, patients with non-fatal acute myocardial infarctions, and patients without any cardiovascular event.

Three patients were operated upon with coronary artery bypass surgery because of intractable angina pectoris and all survived without a subsequent acute myocardial infarction during the follow-up period.

\section{ELECTROCARDIOGRAPHIC ABNORMALITIES}

Of the 193 patients, 7 had left bundle-branch block, 6 had right bundle-branch block, 1 had preexcitation, and 2 had pacemaker electrocardiograms. Of these 16 patients, 3 died, 2 with left bundlebranch block and 1 with right bundle-branch block. None had a non-fatal acute myocardial infarction. These patients were significantly older than the rest of the patients, 70 versus 61 years.

Among the remaining 177 patients there were

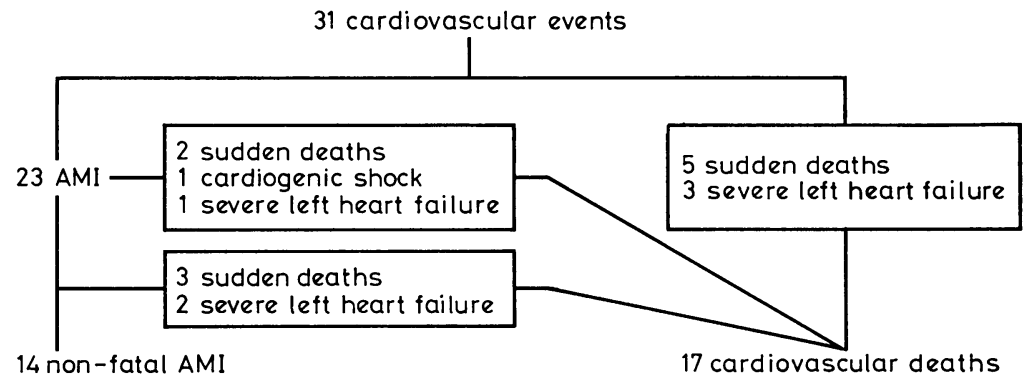

Fig. 1 Cardiovascular events during the follow-up period. 
Table 3 Transient $S T-T$ changes in relation to cardiovascular events

\begin{tabular}{lllll}
\hline & $\begin{array}{l}S T-T \\
\text { changes } \\
n=36\end{array}$ & $\begin{array}{l}\text { No ST-T } \\
\text { changes } \\
n=141\end{array}$ & $\begin{array}{l}\text { Not possible } \\
\text { to evaluate } \\
n=16\end{array}$ & $P$ \\
\hline Cardiovascular event & 19 & 9 & 3 & $<0.001$ \\
No cardiovascular event & 17 & 132 & 13 & $<0.001$ \\
\hline
\end{tabular}

$36(20 \%)$ with transient ST-T changes. Their mean age, 61 years, did not differ from that of patients without transient ST-T changes, mean age 61 years. Three had ST changes only, $21 \mathrm{~T}$ changes only, and 12 patients $S T$ and $T$ changes. The maximal ST-T change from the preceding electrocardiogram occurred in the second registered electrocardiogram in 23 cases and in the third electrocardiogram in the other 13 cases. Among the 15 patients with ST changes, 8 had ST depression and $7 \mathrm{ST}$ elevation, and 6 of the latter were in the form of reduced ST depression from the first registered electrocardiogram. The maximal ST change varied between 1.5 and $4 \mathrm{~mm}$, mean $1.9 \mathrm{~mm}$, and was found in leads III and aVL in 1 case, $C_{2}$ in 3 cases, and leads $\mathrm{CR}_{4}$ and $\mathrm{CR}_{5}$ in 5 cases.

Among the 33 patients with $T$ changes, 3 changes were from negative to positive $T$ wave and the rest developed inverted $T$ waves. Five patients developed symmetrically inverted $\mathrm{T}$ waves. The rest had diphasic $T$ waves, 20 with a positive-negative and 8 with a negative-positive configuration. The maximal change of the $T$ amplitude varied between 1.5 and $17 \mathrm{~mm}$, mean $6.7 \mathrm{~mm}$, and was found in leads III in 3 cases, $\mathrm{CR}_{2}$ in 8 cases, $\mathrm{CR}_{4}$ in 16 cases, and $\mathrm{CR}_{5}$ in 6 cases.

Among the 36 patients with transient ST-T changes there were 9 who died subsequently of cardiovascular causes and 10 who developed a nonfatal acute myocardial infarction, altogether 19 patients $(53 \%)$ with cardiovascular events. Nine patients $(6 \%)$ had a subsequent cardiovascular event without transient ST-T changes during the same follow-up period. Three patients with bundlebranch block, in whom the ST-T changes could not be evaluated, died during the follow-up period
(Table 3). No difference in the incidence of subsequent cardiovascular event was found regarding the localisation of the maximal ST and/or T change, the maximal change of the ST and/or T amplitude, or the type of $\mathrm{T}$ wave, i.e. symmetrical, biphasic positive-negative, or biphasic negative-positive.

\section{NON-CORONARY PATIENTS}

Thirty-two patients $(17 \%)$ had no history of either previous myocardial infarction, angina pectoris, hypertension, hyperlipaemia, or diabetes mellitus. These patients were significantly younger than the rest of the patients. Their ages varied between 30 and 75 years, mean 55 years. None of these patients, including 3 patients with acute pericarditis, showed transient ST-T shifts. All of them survived during the follow-up period and none had a non-fatal acute myocardial infarction. The prognosis in this group compared with the non-acute myocardial infarction patients and with the patients with acute myocardial infarction is shown in Table 4. Exclusion of these patients did not change any of the abovementioned statistical differences between the different groups.

\section{Discussion}

Patients in the present study, admitted because of suspicion of an acute myocardial infarction but without a subsequent diagnosis of acute myocardial infarction, appear to run a high risk for cardiovascular death with a 1 -year mortality of 9 per cent. The majority of the patients had coronary artery disease. Only 17 per cent could be classified as noncoronary cases, and they had an excellent prognosis without any deaths or subsequent myocardial infarctions.

In a recent study (Schroeder et al., 1977) of patients admitted to the CCU with chest pain 70 per cent did not have an acute myocardial infarction, and of these 18 per cent was judged to have noncardiac chest pain. Among patients with prolonged ischaemic chest pain and transient ST changes, without acute myocardial infarction, a 4 per cent 1 -month and a 10 per cent 1-year mortality was

Table 4 One year incidence of cardiovascular events for patients with acute myscardial infarction, patients with non-acute myocardial infarction and non-coronary patients discharged from CCU

\begin{tabular}{|c|c|c|c|c|c|c|}
\hline & $\begin{array}{l}\text { Patients } \\
\text { infarction } \\
n=187\end{array}$ & myocardial & $\begin{array}{l}\text { Non-acut } \\
\text { patients } \\
n=193\end{array}$ & $\begin{array}{l}\text { dial infarction } \\
\%\end{array}$ & $\begin{array}{l}\text { Non-cor } \\
\text { patients } \\
n=32\end{array}$ & $\%$ \\
\hline $\begin{array}{l}\text { Non-fatal acute myocardial infarction } \\
\text { Cardiovascular deaths } \\
\text { Cardiovascular events }\end{array}$ & $\begin{array}{l}27 \\
32 \\
59\end{array}$ & $\begin{array}{l}14 \\
17 \\
32\end{array}$ & $\begin{array}{l}14 \\
17 \\
31\end{array}$ & $\begin{array}{r}7 \\
9 \\
16\end{array}$ & $\begin{array}{l}0 \\
0 \\
0\end{array}$ & $\begin{array}{l}0 \\
0 \\
0\end{array}$ \\
\hline
\end{tabular}


found. If the non-coronary cases in the present study are excluded, a 1-year mortality of 11 per cent is found. This mortality is almost the same as that after acute myocardial infarction (Hofvendahl, 1971). Dussia et al. (1976) found that patients admitted to the CCU with a history typical of myocardial infarction appeared to have a comparable in-hospital mortality rate after 48 hours, a comparable 1-year mortality rate, and a comparable incidence of recurrent myocardial infarction during the first year, whether or not they developed confirmatory electrocardiographic or serum enzyme changes.

Ten $(40 \%)$ of the 23 deaths that occurred in the material of Schroeder et al. (1977) were sudden (within 24 hours) and 13 were caused by acute myocardial infarction or its complications. A similar proportion of sudden death (59\%) was also found in the present study. Recently clinical studies have reported a reduction in sudden death with the routine use of beta-adrenergic blocking agents in postinfarction patients (Ahlmark et al., 1974; Wilhelmsson et al., 1974; Multicentre International Study, 1975). These results provide a basis for therapeutic trials in the type of patients discussed in the present study, preferably in a selected high-risk subgroup.

In an earlier report, Lopes et al. (1974) were unable to identify the patients who died subsequently from cardiac causes when comparing serial ST-T changes, frequency of premature ventricular beats, episodes of ventricular tachycardia or fibrillation, and conduction defects during hospitalisation with those of the group who survived during the follow-up. However, in the present study a highrisk group could be selected by transient ST-T changes in serial electrocardiograms. The sensitivity of the ST-T changes might be improved by a more frequent electrocardiographic recording or by ST-T mapping.

Transient ST-T changes have often been reported in association with conditions regarded as severe myocardial ischaemia, such as unstable angina, impending myocardial infarction, intermediate coronary syndrome (Bertolasi et al., 1974; Berndt et al., 1975; Chahine, 1975; Cairns et al., 1976; Alison et al., 1978) and is sometimes included as a major or minor criterion of unstable angina (Bertolasi et al., 1974; Berndt et al., 1975; National Cooperative Study Group, 1976; Day et al., 1977; Hultgren et al., 1977).

Another explanation of the ST-T changes might be an acute myocardial infarction, which is either too small to be detected by conventional enzymes or its onset is too early before admission to allow an enzyme diagnosis. In the first case it is known that 10 to 20 per cent of patients admitted because of suspected acute myocardial infarction, but with a ruled-out diagnosis, have increases in enzyme levels within the normal range and a prognosis similar to true acute myocardial infarction (Säwe, 1972). However, this author did not report whether the enzyme increases were correlated to any ST-T changes. Furthermore, patients in the present study with ST-T changes did not have significantly different maximal AST (SGOT) values or change of AST activity. This diagnostic problem is now being studied prospectively by a more frequent sampling of enzymes as well as by a more sensitive and specific enzyme method (Lundin and Styrélius, 1978).

In the second case, analysis of LDH could have been of value but was not routinely used in the present study. However, patients with ST-T changes did not have a significantly longer delay between onset of symptoms and admission to the CCU than patients without these electrocardiographic abnormalities. The important clinical finding is that, whether these patients have had a small acute myocardial infarction or not, they constitute a high risk group.

Bodenheimer et al. (1977) investigated the pathophysiological significance of $S T$ and $T$ wave abnormalities in 21 patients with the intermediate coronary syndrome, characterised by recurrent chest pain at rest associated with significant new ST or $T$ wave abnormalities, or both, and no new $Q$ waves in the surface electrocardiogram at the time of open heart coronary bypass surgery. These patients did not have $Q$ waves either in the intraoperative epicardial or postoperative surface electrocardiogram. In 7 patients, a transmural biopsy specimen was also obtained from the ischaemic area. All showed histologically normal myocardium without evidence of early inflammatory or necrotic tissue.

The form of the $T$ wave also merits some interest. In situations of coronary insufficiency it has been described as a deep symmetrically inverted $\mathrm{T}-\mathrm{a}$ socalled 'coronary ' $T$ ' (World Health Organization, 1970). In the present study only 5 patients $(15 \%)$ had symmetrically inverted $T$ waves while in the rest they were diphasic, an example of which is shown in Fig. 2.

In conclusion, patients admitted to the CCU because of suspected acute myocardial infarction but without a subsequent diagnosis of acute myocardial infarction have a high risk for cardiovascular death with a 1-year mortality of 9 per cent and a 1-year incidence of non-fatal acute myocardial infarction of 7 per cent. The majority of the patients had coronary artery disease. Only 17 per cent could 


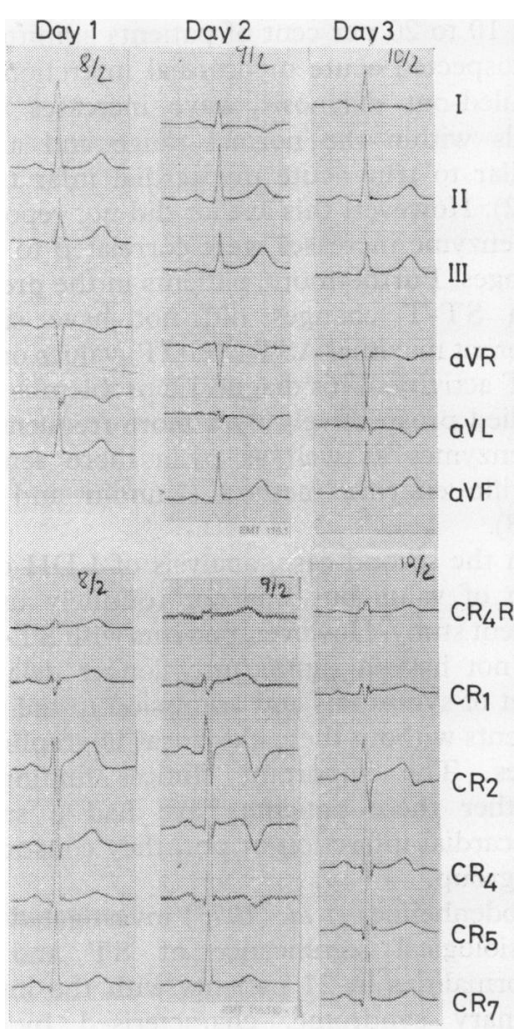

Fig. 2 Example of transient $S T-T$ changes.

be classified as non-coronary cases, and they had an excellent prognosis without any deaths or subsequent acute myocardial infarctions. The occurrence of transient ST-T changes selected a subgroup of patients with a high risk for subsequent non-fatal acute myocardial infarctions and cardiovascular death. This high risk subgroup provides a basis for more aggressive diagnostic and therapeutic interventions.

This study was supported by grants from the Swedish National Association against Heart and Chest Diseases.

\section{References}

Ahlmark, G., Saetre, H., and Korsgren, M. (1974). Reduction of sudden deaths after myocardial infarction. Lancet, $2,1563$.

Alison, H. W., Russell, R. O., jun, Mantle, J. A., Kouchoukos, N. T., Moraski, R. E., and Rackley, C. E. (1978). Coronary anatomy and arteriography in patients with unstable angina pectoris. American fournal of Cardiology, 41, 204-209.

Berndt, T. B., Miller, D. C., Silverman, J. F., Stinson, E. B., Harrison, D. C., and Schroeder, J. S. (1975). Coronary bypass surgery for unstable angina pectoris. Clinical followup and results of postoperative treadmill electrocardiograms. American fournal of Medicine, 58, 171-176.

Bertolasi, C. A., Trongé, J. E., Carreño, C. A., Jalon, J., and Ruda Vega, M. (1974). Unstable angina-prospective and randomized study of its evolution, with and without surgery. American fournal of Cardiology, 33, 201-208.

Bodenheimer, M. M., Banka, V. S., Trout, R. G., Hermann, G. A., Pasdar, H., and Helfant, R. H. (1977). Pathophysiologic significance of $S-T$ and $T$ wave abnormalities in patients with the intermediate coronary syndrome. American fournal of Cardiology, 39, 153-158.

Cairns, J. A., Fantus, I. G., and Klassen, G. A. (1976). Unstable angina pectoris. American Heart fournal, 92, 373-386.

Chahine, R. A. (1975). Unstable angina. The problem of definition. British Heart fournal, 37, 1246-1249.

Corday, E. (1977). Symposium on identification and management of the candidate for sudden cardiac death. Introduction. American Fournal of Cardiology, 39, 813-815.

Day, L. J., Thibault, G. E., and Sowton, E. (1977). Acute coronary insufficiency. British Heart fournal, 39, 363-370.

Dussia, E. E., Cromartie, D., McGraney, J., Mead, G., and Wenger, N. K. (1976). Myocardial infarction with and without laboratory documentation-one year prognosis. American Heart fournal, 92, 148-151.

Freeman, J. W., and Loughhead, M. G. (1972). Prodromal angina preceding acute myocardial infarction. Medical Fournal of Australia, 1, 325-326.

Helmers, C. (1974). Short and long-term prognostic indices in acute myocardial infarction. A study of 606 patients initially treated in a coronary care unit. Acta Medica Scandinavica, Suppl. 555.

Hofvendahl, S. (1971). Influence of treatment in a coronary care unit on prognosis in acute myocardial infarction. A controlled study in 271 cases. Acta Medica Scandinavica, Suppl. 519.

Hultgren, H. N., Pfeifer, J. F., Angell, W. W., Lipton, M. J., and Bilisoly, J. (1977). Unstable angina: comparison of medical and surgical management. American fournal of Cardiology, 39, 734-740.

Lopes, M. G., Spivack, A. P., Harrison, D. C., and Schroeder J. S. (1974). Prognosis in coronary care unit noninfarction cases. Fournal of the American Medical Association, 228, 1558-1562.

Lundin, A., and Styrélius, I. (1978). Sensitive assay of creatine kinase isoenzymes in human serum using $M$ subunit inhibiting antibody and firefly luciferase. Clinica Chimica Acta, 87, 199-209.

Moss, A. J., DeCamilla, J., and Davis, H. (1977). Cardiac death in the first 6 months after myocardial infarction: potential for mortality reduction in the early posthospital period. American fournal of Cardiology, 39, 816-820.

Multicentre International Study (1975). Improvement in prognosis of myocardial infarction by long-term betaadrenoreceptor blockade using practolol. British Medical fournal, 3, 735-740.

National Cooperative Study Group (1976). Unstable angina pectoris: national cooperative study group to compare medical and surgical therapy. American fournal of Cardio$\log y, 37,896-902$.

Säwe, U. (1972). Early diagnosis of acute myocardial infarction with special reference to the diagnosis of the intermediate coronary syndrome. Acta Medica Scandinavica, Suppl. 545.

Schroeder, J. S., Lamb, I. H., and Harrison, D. C. (1977). Patients admitted to the coronary care unit for chest pain: high risk subgroup for subsequent cardiovascular death. American fournal of Cardiology, 39, 829-832.

Solomon, H. A., Edwards, A. L., and Killip, T. (1969). 
Prodromata in acute myocardial infarction. Circulation, 40, 463-471.

Vedin, A., Wilhelmsen, L., Wedel, H., Pettersson, B., Wilhelmsson, C., Elmfeldt, D., and Tibblin, G. (1977). Prediction of cardiovascular deaths and non-fatal reinfarctions after myocardial infarction. Acta Medica Scandinavica, 201, 309-316.

Vismara, L. A., Miller, R. R., Price, J. E., Karem, R., DeMaria, A. N., and Mason, D. T. (1977). Improved longevity due to reduction of sudden death by aortocoronary bypass in coronary atherosclerosis. Prospective evaluation of medical versus surgical therapy in matched patients with multivessel disease. American fournal of
Cardiology, 39, 919-924.

Wilhelmsson, C., Vedin, J. A., Wilhelmsen L., Tibblin, G., and Werkö, L. (1974). Reduction of sudden deaths after myocardial infarction by treatment with alprenolol. Lancet, 2, 1157-1160.

World Health Organization (1970). Ischemic Heart Disease Registers. WHO, Regional office for Europe, Copenhagen.

Requests for reprints to Dr O. Nyquist, Department of Medicine, Huddinge Hospital, S-141 86 Huddinge, Sweden. 